\title{
A novel flexible tool with rotary ultrasonic spindle for fine grinding of tungsten carbide
}

\author{
Albert Wen-Jeng Hsue ${ }^{*}$ and Yi-Zhong Zheng \\ Department of Mold and Die Engineering, National Kaohsiung University of Science and Technology, \\ Taiwan
}

\begin{abstract}
Tungsten carbide is a typical difficult-to-cut material by conventional machining processes. In this paper, a novel design of flexible abrasives tool combined with a rotary ultrasonic machining (RUM) spindle is conducted to reduce the labor force significantly. The newly designed flexibility of tool-tip is aimed at preventing overcutting from the $\mathrm{CNC}$ grinding. The grinding conditions with resulted surface morphology of the tungsten steel were investigated through Taguchi design of experiment and ANOVA analysis. The machining capability of the novel flexible tool is compared with conventional tools through specific grinding paths under proper operational conditions.
\end{abstract}

\section{Introduction}

As a very strong mould material, tungsten carbide is usually difficult to cut by traditional machining processes. Its hardness was usually risen up to 85 to 91 HRA. At the other hand, the machined surface roughness by most of the CNC machining cannot reach mirror-like quality; and they must rely on secondary polishing for very period in the normal processing. In this paper, a novel flexible abrasives tool combined with a rotary ultrasonic machining (RUM) spindle is conducted to reduce the labour force for polishing significantly. The newly designed flexibility of tools is aimed at preventing overcutting from the general CNC machine grinding. The grinding conditions with resulted surface morphology of the tungsten steel were investigated and analyzed. The suitable operating conditions are studied through Taguchi design of experiments and ANOVA analysis.

The ultrasonic assisted machining (UAM) was consider as a suitable option for the processing of difficult-to-cut materials in the past decades [1]. In the recent years, the rotary ultrasonic machining (RUM) spindle was further proposed to successfully assist the machining processes of hard and brittle materials [2-3]. It provides much better properties than UAM in both increasing tool life and reducing the cutting force. Therefore, it is emerging in the production fields up to date. For example, Shen et al. [4] revealed that RUM can increase the material removal rate of ceramics, although there were micro cracks remained at the cutting edge. But the self-dressing of tool abrasives by using the RUM spindle seems trivial since the impact effect of rotary ultrasonic causing the small breakage

*Corresponding author:albert.hsue@kuas.edu.tw 
of abrasives. Guo et al. [5] verified that the surface integrity of cutting edge of brittle materials conducted by RUM is better than that by UAM. They also confirmed the superior quality of RUM over conventionally done by the RAM ultrasonic machining.

For fundamental insights of grinding, Ismail et al. [6] proposed a concept of effective radius to describe the region of proper geometrical transcription and better surface roughness conducted with RUM assisted grinding. The quantity of remaining abrasives resident within the circle of that effective radius is an essential index to evaluate the grinding effect of RUM assistance. It is also a good index for evaluation of worn-out or tool life.

Wang et. al. [7] proposed a concept of system matching for RUM type of grinding of titanium in 2014. They reveal the interaction between main factors, and the analysis technology for improving surface integrity under the system matching conditions. Wang et. al. [8] also investigated the grinding of brittle materials further with this system concept in the same year. They further establish a predictive model for the grinding force and the surface integrity with RUM effect. Before that, Hu et. Al. [9] have proposed a report on modeling of material removal rate in rotary ultrasonic machining. They simulate the effects of main factors on the material removal rate by establishing a removal model through design of experiments (DOE) and ANOVA analysis.

In the lab, Hsue and Wang also proposed a series of RUM drilling and grinding experiments on brittle materials, such as $\mathrm{ZrO} 2$, Sapphire and Na-Ca glass through TaguchiANOVA analysis in the 2015 [10]. They also investigated the machining resistance response, tool life and the effects of the paths (cycloid VS. linear) on the removal efficiency and the surface integrity. It confirmed that RUM provided much longer tool life, smaller machining force and lower roughness compared to the conventional grinding processes. However, the material removal rate (MRR) depends on not only the ultrasonic assistance, but also the operational conditions, and even the machining paths. In which, cycloid paths provided not only higher MRR but also better roughness under the assistance of RUM.

This research is aimed at experiments with a newly designed flexible tool and contribution to the polishing processes of a mould made of tungsten carbide. The maximum MRR and the minimum three-dimensional surface roughness with reasonable power consumption were set as the targets. Also, the polishing resistance reflected by the RUM machining processes are investigated.

First of all, the Taguchi's L16 orthogonal experiments are conducted using the rough abrasives of \# 400 meshes tool. The major contribution factors for enhancing material removal rate are investigated. The optimized combination of operational conditions is also analysed by ANOVA and compared with two kinds of tool holders. Secondary, the fundamental polishing investigation by using \#1000 abrasives in grain size of $13 \mu \mathrm{m}$ and proper cutting depth combined with the RUM spindle are conducted. Their polishing forces vs. feed rate, and the spindle speed are also investigated and analysed. For further improvement of finishing processes, effects of cycloid paths with and without flexible tool under RUM are compared to conventional linear paths.

\section{Experiment setup and design of the flexible tool}

\subsection{Experimental setup}

To investigate the effect of the novel tool for RUM grinding, we adopted a RUM spindle built on a machnie tool, VU-5, by a local machine builder, Tongtai machine \& tool Co. The ultrasonic power consumption of its rotary spindle can be adjusted from $0 \%$ to $100 \%$, therefroe, with certain power and without ultrasnoic vibrataion can be compared in the 
experiments. As shown in Figure 1, the main component of the experimental setup is described as followed. In which, (1) indicates the RUM spindle, (2) : flexible tool holder and the diamond abrasive tool, (3) : workpiece, (4) : fixture jig for workpiece, (5) : six axes force sensor, (6) : main clamper vise mounted on machine table, (7): Reinyshaw noncontact tool calibrator. In which, the fixture platelet (4) milled to a square cavity in advanced $\mathrm{i}$ saimed at holding workpiece and connected to the force sensor. The 6 axial force sensor (5) with a protection acrylic box was then mounted on the main vise (6). The cutting force exerted on workpiece was measured and amplified through a signal conditioner and then acquired by a notebook PC through DAQ with USB interface. To protect the entire instrument setup from machining fluid flushing, they are covered with a sheet of plastic cloth as shown in Figure 1(a).

As shown in Figure 1(b), this research adopts tungsten carbide in type C01 as workpiece sample, which was fabricated by Cheng-Chang carbide Co., Ltd. Its grain size distributes from 1.0 to $2.0 \mu \mathrm{m}$, with the density of $15.0 \mathrm{~g} / \mathrm{cm}^{3}$, hardness of 90-90.5 HRA. It is typically a sort of strong mold material for fastening components such as drawing and forging of the bolt heads. Typically, tungsten-carbide is a chemical compound containing equal parts of tungsten and carbon atoms. In its most basic form, tungsten carbide is a fine gray powder, but it can be pressed and formed into shapes for use in industrial machinery, cutting tools, moulds, other tools and instruments and etc. Tungsten carbide is approximately twice as strong as steel, with a strong Young's modulus. It is so tough with comparable hardness with corundum $\left(\alpha-\mathrm{Al}_{2} \mathrm{O}_{3}\right)$ and can only be polished and finished with abrasives of superior hardness such as cubic boron nitride (CBN) or diamond powder, and wheels.

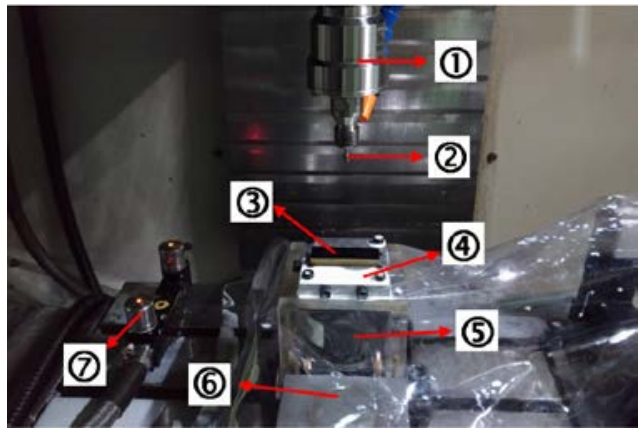

(a)

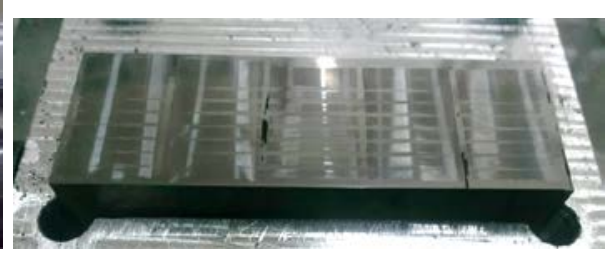

(b)

Fig. 1. (a)Setup of the RUM spindle with flexible abrasive tool, (b) Tungsten carbide after grinding testing.

\subsection{Design of experiment - preparing and planning}

This research investigates the MRR and surface integrity of RUM grinding with the newly developed flexible RUM tool. In the rough machining stage, main factors include feedrate, RUM consumption power, spindle speed, and grinding depth. The surface terrain of work after tests is also investigated. Preparing processes adopted a CBN ceramic milling tool with $16 \mathrm{~mm}$ diameter, succeeded with a $6 \mathrm{~mm}$ diameter of \#230 tool and another \#400 abrasive tools for rough grinding.

The assembly of the proposed flexible tool holder is depicted in a conceptual plot as shown in Figure 2, and the customized abrasive tool with diameters $12 \mathrm{~mm}$ and $6 \mathrm{~mm}$ are shown in Figure 3. The flexible tool holder involvoes a screw nut, two sheets of spring ring, an innner shaft for holding tool with inner threads, linear sleeve bearing for holding the innner shaft, fix-pin for fixing the innner shaf to the tool holder's shell. Then, the tool holder 
combined with customized abrasive tool was adopted to the spindle of the machine tools.

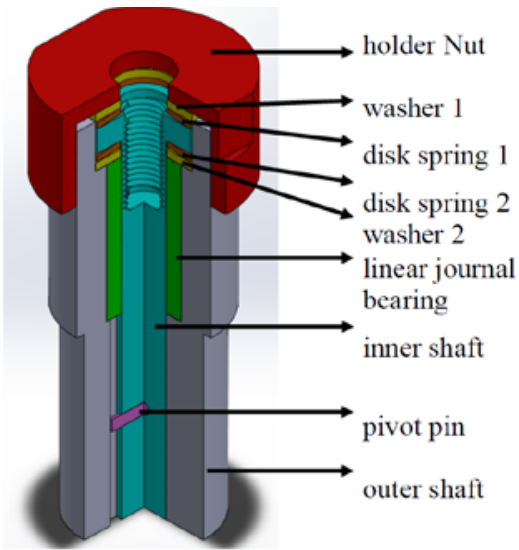

Fig. 2. Assembly plot of the proposed flexible tool holder.

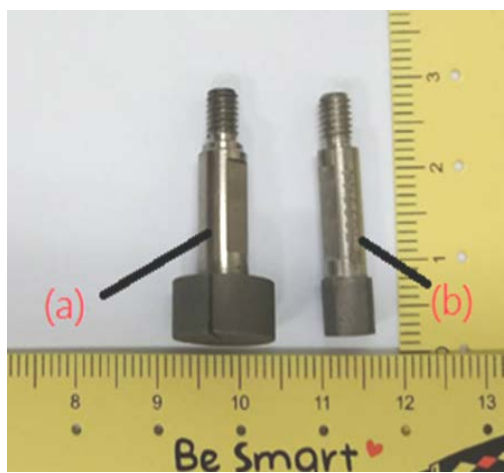

Fig. 3. The customized abrasive tool with diameters of (a) $12 \mathrm{~mm}$ and (b) $6 \mathrm{~mm}$.

Preliminary plans from the roughing to finish grinding were first designed. Rough grinding

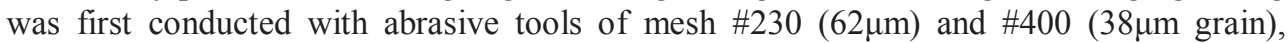
combined with surveying factors include tool types and grinding depth. The spindle speed is fixed at $5 \mathrm{krpm}$, feed rate at $10 \mathrm{~mm} / \mathrm{min}$, and with RUM in $100 \%$ power or without RUM $(0 \%)$, and grinding depths from $2,4,6,8$ to $10 \mu \mathrm{m}$. For finishing stage, spindle speeds was

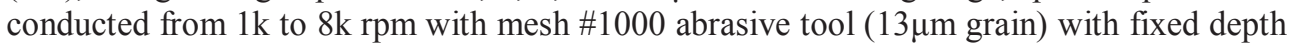
$3 \mu \mathrm{m}$ and fixed feedrate of $10 \mathrm{~mm} / \mathrm{min}$. And then, machining feedrate was conducted from 5 , $10,20,40$ to $80 \mathrm{~mm} / \mathrm{min}$ with fixed $5 \mathrm{k} \mathrm{rpm}$ and the fixed depth $3 \mu \mathrm{m}$.

Design of experiment (DOE) for RUM grinding with the proposed flexible tool holder was conducted based on Taguchi-ANOVA method. The middle-finishing experiment through L16 orthogonal array adopted a $6 \mathrm{~mm}$ diameter tool with mesh \#400 abrasives. The surface integrity was measured by a KEYENCE VK-X200 laser microscope, and the removal volume was estimated from the machined slot based upon the measured profiles.

Table 1. L16 orthogonal array for midterm-finishing of Tungsten carbide by DOE.

\begin{tabular}{c|ccccc}
\hline $\begin{array}{c}\text { Test } \\
\text { No }\end{array}$ & $\begin{array}{c}\text { Spindle } \\
(\mathrm{rpm})\end{array}$ & $\begin{array}{c}\text { Feedrate } \\
(\mathrm{mm} / \mathrm{min})\end{array}$ & $\begin{array}{c}\text { depth } \\
(\mu \mathrm{m})\end{array}$ & $\begin{array}{c}\text { Tool- } \\
\text { hoolder }\end{array}$ & RUM \\
\hline 1 & 4000 & 10 & 3 & Fixed & on \\
2 & 4000 & 20 & 6 & Fixed & on \\
3 & 4000 & 30 & 9 & Flexible & off \\
4 & 4000 & 40 & 12 & Flexible & off \\
5 & 5000 & 10 & 6 & Flexible & off \\
6 & 5000 & 20 & 3 & Flexible & off \\
7 & 5000 & 30 & 12 & Fixed & on \\
8 & 5000 & 40 & 9 & Fixed & on \\
9 & 6000 & 10 & 9 & Fixed & off \\
10 & 6000 & 20 & 12 & Fixed & off \\
11 & 6000 & 30 & 3 & Flexible & on \\
12 & 6000 & 40 & 6 & Flexible & on \\
13 & 7000 & 10 & 12 & Flexible & on \\
14 & 7000 & 20 & 9 & Flexible & on \\
15 & 7000 & 30 & 6 & Fixed & off \\
16 & 7000 & 40 & 3 & Fixed & off \\
\hline
\end{tabular}


Design of experiment for final finishing through L9 orthogonal array adopted an abrasive tool with \#1000 mesh grits. The contribution of dominant factors and the optimum combination of the operation conditions are derived from Taguchi-ANOVA analysis. The optimization combination is then carefully verified by a set of confirmed experiments.

Table 2. L9 DOE orthogonal array for final finishing by flexible tool.

\begin{tabular}{c|ccc}
\hline $\begin{array}{c}\text { Test } \\
\text { No }\end{array}$ & $\begin{array}{c}\text { Spindle } \\
(\mathrm{rpm})\end{array}$ & $\begin{array}{c}\text { Feedrate } \\
(\mathrm{mm} / \mathrm{min})\end{array}$ & $\begin{array}{c}\text { Power of Ultrasonic } \\
\text { generator }(\%)\end{array}$ \\
\hline 1 & 4000 & 9 & 0 \\
2 & 4000 & 12 & 30 \\
3 & 4000 & 15 & 100 \\
4 & 5000 & 9 & 30 \\
5 & 5000 & 12 & 100 \\
6 & 5000 & 15 & 0 \\
7 & 6000 & 9 & 100 \\
8 & 6000 & 12 & 0 \\
\hline
\end{tabular}

\section{Experiment results and discussions}

\subsection{Response of surface integrity to grinding depth}

The first set of rough experiments adopted a $6 \mathrm{~mm}$ abrasive tool with \#230 grits (about $62 \mu \mathrm{m})$. The fixed spindle speed at $5 \mathrm{k}$ rpm results in a tangential velocity of $1.57 \mathrm{~m} / \mathrm{s}$, and feedrate is fixed at $10 \mathrm{~mm} / \mathrm{min}$. Effect of grinding depth with RUM and without RUM, associated with fixed and flexible abrasive tool is compared and discussed as follows.

Tree dimensional surface roughness $(\mathrm{Sa})$ with the fixed and the novel flexible tools are conducted and compared, respectively. With the fixed tools, the surface roughness decades with the grinding depth, no matter if the RUM is applied. But the minimum seems appeared at the $6 \mu \mathrm{m}$ depth. The fixed tool with RUM produced results no better than that without RUM. Although the roughness trend looks similar for those with flexible tools, however, the flexible RUM seems much more sensitive than fixed tools and produced better roughness than that without RUM, but the deviations at shallow depth (which is less than or equal to $4 \mu \mathrm{m}$ depth) are relatively large. The minimum roughness achieved $\mathrm{Sa} 0.48 \mu \mathrm{m}$ at $8 \mu \mathrm{m}$ depth is concluded.

Effect of grinding depth on the profiles is conducted from profile measurement through Mitutoyo SJ-400 instrument. As shown in Figure 4, the material removal rate can be estimated from the cross-section area of approximated trapezoid in machined slot. The fixed tool with RUM, as shown in Figure 4(a), produced deeper and more integrity profile than that with flexible tool in Figure 4(b).

The MRR wth RUM and No-RUM are calculated from the product of grinding length and this cross-section area as shown in Figure 4. The removal ability of both fixed tool and the flexible rool looks integrity. The MRR is in a positive proportional relationship to grinding depth for both cases. But with the fixed tools, as shown in Figure 5(a), the MRR of both wth RUM or No-RUM produced no obvious difference except lower depth under $4 \mu \mathrm{m}$. However, from the Figure 5(b), the MRR without RUM is almost 3 times of that with RUM, revealing the flxiblity of novel tool combined with RUM producees less removal volume rate. 
(a)

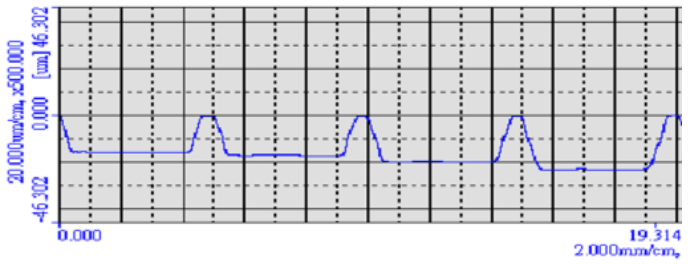

(b)

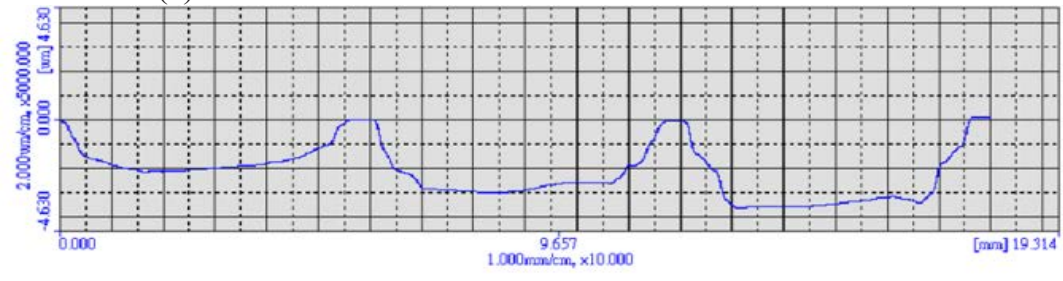

Fig. 4. Effect of grinding depth on machined profiles without RUM, but with (a) the fixed tools $4,6,8,10 \mu \mathrm{m}$, (b) the flexible tools $4,6,8 \mu \mathrm{m}$.

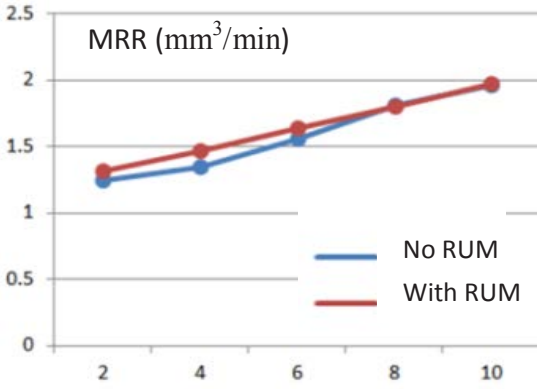

(a) depth $(\mu \mathrm{m})$

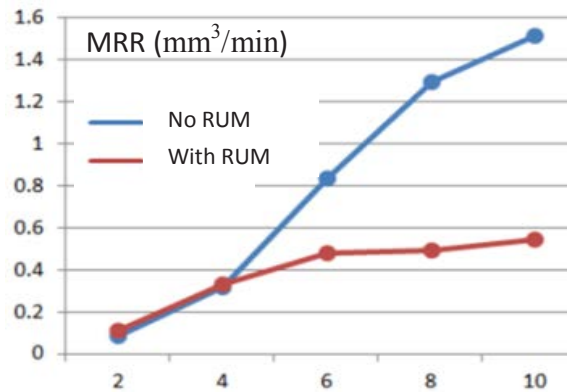

(b) depth $(\mu \mathrm{m})$

Fig. 5. Response of surface roughness to grinding depth with (a) the conventional fixed tools, and (b) the flexible tools.

As shown in Figure 6, the grinding force is in a positive proportional relationship to grinding depth for both cases. No matter flexible tool or fixed tool types, as shown in Figures 6 (a), the grinding force of with RUM can reduce the grinding force significantly compared to that without RUM. From the Figure 6(a), the resistance force without RUM is almost 2.3 times of that with RUM conducted in depth of $10 \mathrm{um}$ for conventional. At the other hand as shown in Figure 6(b), it is almost 3 times difference for flexible tool, revealing the effect of RUM on saving tool " "ng.

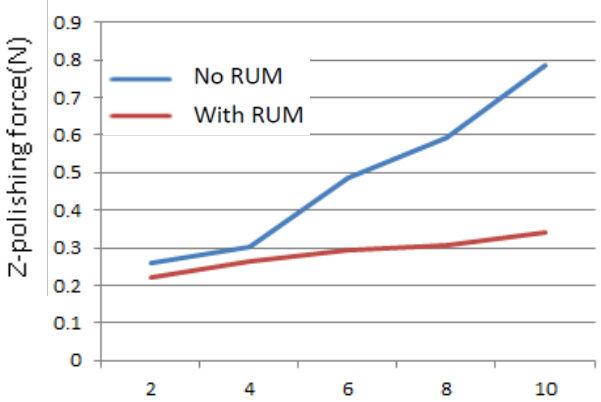

(a) depth $(\mu \mathrm{m})$

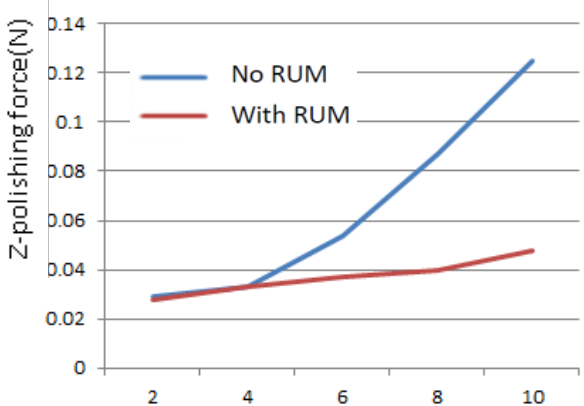

(b) depth $(\mu \mathrm{m})$

Fig. 6. Effect of grinding depth on grinding force with (a) the conventional fixed tools, and (b) the flexible tools. 
Therefore, the Z-axis polishing force increases with the increasing grind-depth, and decreases with the spindle speed. Generally, the polishing force by using RUM is smaller than that by no-RUM and the difference gets larger as the grinding depth gets deeper.

\subsection{Response of surface roughness to the spindle speed and the feed rate}

The experiments since from this section are all conducted with the novel flexible tools with $6 \mathrm{~mm}$ diameter and the abrasive diamond grains of \#1000. The experimental aims at the response of surface roughness and profile to the spindle speed, through $1 \mathrm{krpm}$ to $7 \mathrm{k} \mathrm{rpm}$, or tangential velocity of $19 \mathrm{~m} / \mathrm{s}$ to $151 \mathrm{~m} / \mathrm{s}$. Its grinding depth is fixed at $3 \mu \mathrm{m}$ associated with $10 \mathrm{~mm} / \mathrm{min}$ of feedrate, and the machining path is a single round trips in a linear way (go forth and come back to its origin). As shown in Figure7, the 3D surface roughness reveals decreasing trends as the spindle speed increases, no matter if rotary ultrasonic wave is applied or not. However, with ultrasonic assistance its Sa is apparently depressed both at the lowest speed and at higher speed above $132 \mathrm{~m} / \mathrm{s}$. The best Sa $0.25 \mu \mathrm{m}$ appears at $132 \mathrm{~m} / \mathrm{s}$, which is about $24 \%$ improved from the case without ultrasonic assistance.

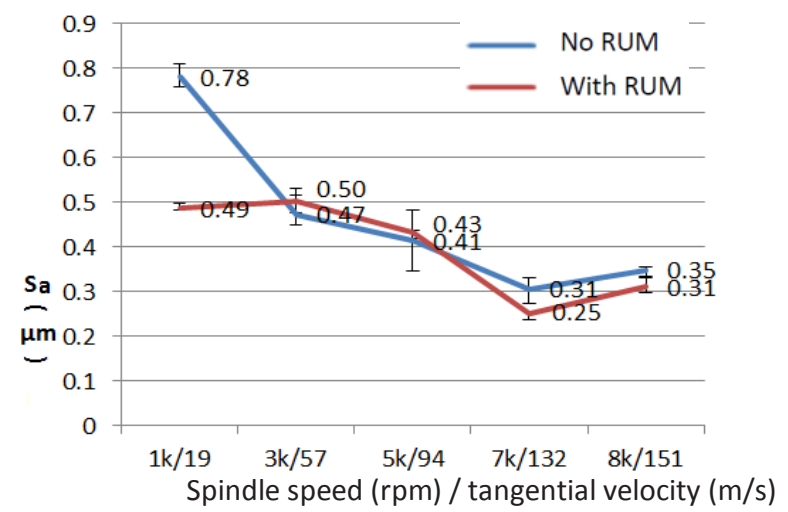

Fig. 7. Response of surface roughness to the spindle speed.

On the other hand, the response of surface roughness and profile to the feedrate is conducted with fixed spindle speed at $5 \mathrm{k} \mathrm{rpm}(94 \mathrm{~m} / \mathrm{s})$. As shown in Figure 8, As the feedrate increases from $5 \mathrm{~mm} / \mathrm{min}$ to even $40 \mathrm{~mm} / \mathrm{min}$, there is a decreasing trends for Sa, no matter with rotary ultrasonic assistance or not. In general, the ground surface roughness with ultrasonic is better than that without ultrasonic. Therefore, the best 3D surface roughness appears at $20 \mathrm{~mm} / \mathrm{min}$ for $\mathrm{Sa} 0.56 \mu \mathrm{m}$ with ultrasonic assistance.

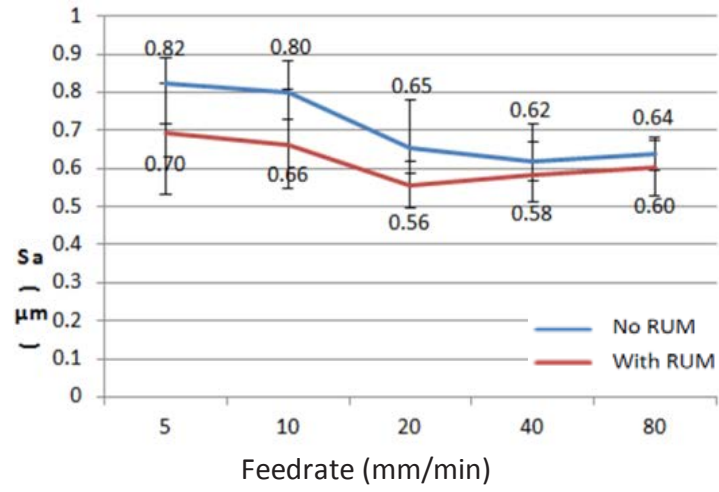

Fig. 8. Response of surface roughness to the machining feed rate. 


\subsection{Finishing experiments and comparison on polishing paths}

As shown in Figure 9, by using \#400 grit abrasives tools, the $\mathrm{S} / \mathrm{N}$ ratio of MRR for a midterm finishing experiments is obtained according to the L16 array in Table 1. From the chart of $\mathrm{S} / \mathrm{N}$ ratio, the dominant contribution is evaluated and ranked as Grinding depth, Spindle speed, Feed rate, and level of RUM. The optimum combination of operation conditions for the highest MRR is $5 \mathrm{k} \mathrm{rpm}$, feed rate at $5 \mathrm{~mm} / \mathrm{min}, 12 \mu \mathrm{m}$ depth, with RUM and the flexible tool. From the first two columns, the higher feedrate associated with the speed above $5 \mathrm{k}$ rpm causes poor MRR. The reason is due to the collapse of the diamond abrasive from the tool-tip in those conditions. Since removal volume is estimated from the product of the actual cross-section as shown in Figure 4. And saving the grinding efficiency, the worn out of tool tip reduces the removal rate significantly.

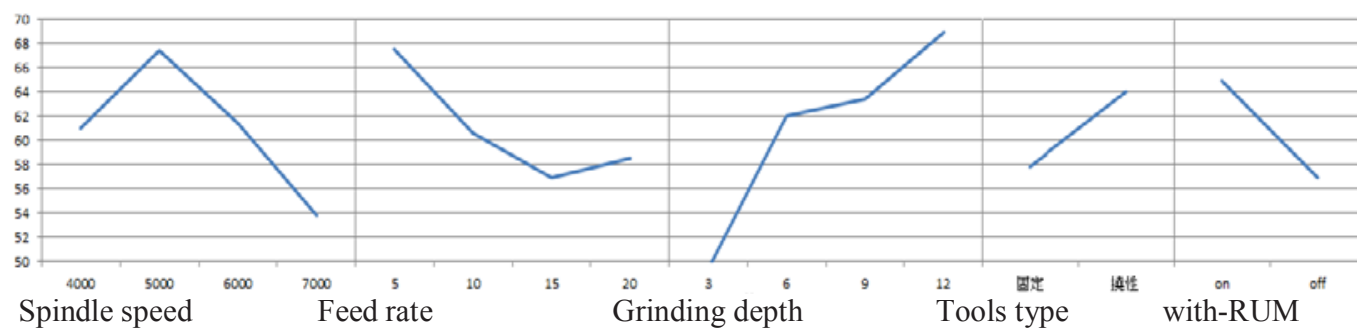

Fig. 9. S/N ratio of MRR for a midterm finishing (\#400 grit) from L16 array.

By using $10 \mathrm{~mm}$ diameter tools with abrasives of \#1000 grits, as shown in Figure 10, the $\mathrm{S} / \mathrm{N}$ ratio of surface roughness for final finishing experiments in a L9 array (Table 2) is depicted. The grinding depth is fixed as $3 \mu \mathrm{m}$, with flexible tool. According to ANOV analysis, the rank of dominant contribution to the roughness is Spindle speed, Ultrasonic power level, and Feedrate. The optimum combination of operation conditions for the lowest roughness is $5 \mathrm{k} \mathrm{rpm}, 9 \mathrm{~mm} / \mathrm{min}$, and $100 \%$ full RUM power, and it contributed to Sa $0.454 \mu \mathrm{m}$. The confirm experiment revealed a Sa $0.418 \mu \mathrm{m}$, deviates $7.6 \%$ from the prediction result. Observation from Figure 10 reveals above $5 \sim 6 \mathrm{k} \mathrm{rpm}$, the tool worn out cancels the advantage of high spindle speed on surface roughness. Moreover, higher ultrasonic power level seems improve the surface roughness a little bit.

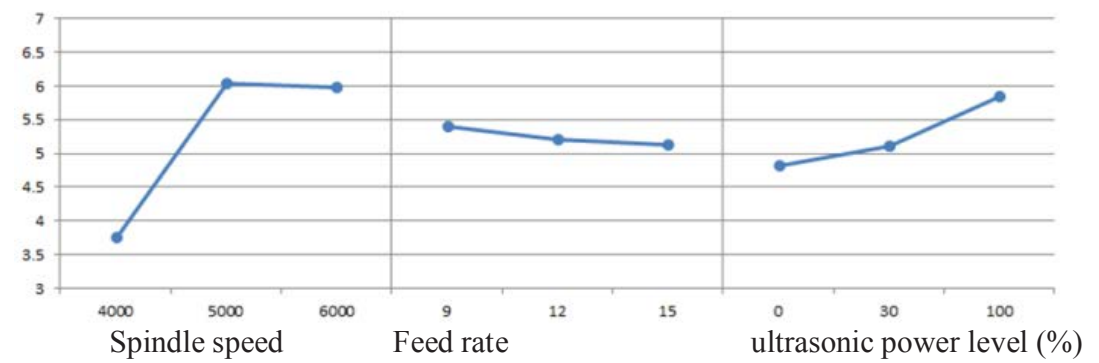

Fig. 10. $\mathrm{S} / \mathrm{N}$ ratio of surface roughness for final finishing in linear path (flexible tool)

Another strategy to adopt cycloid path as shown in Figure 11, the Taguchi Finishing L9 experiments reveal similar trends as that in Figure 11, except the effect of ultrasonic power. The optimum combination of operation conditions for the lowest roughness is $5 \mathrm{k} \mathrm{rpm}$, feedrate $9 \mathrm{~mm} / \mathrm{min}$, without RUM power, and it contributed to Sa $0.172 \mu \mathrm{m}$ according to the ANOVA analysis. However, confirm experiment revealed a Sa $0.185 \mu \mathrm{m}$, deviates $7 \%$ from the prediction result. $0.172 \mu \mathrm{m}$, which is much smaller than that roughness by linear path as shown in Figure 10. 


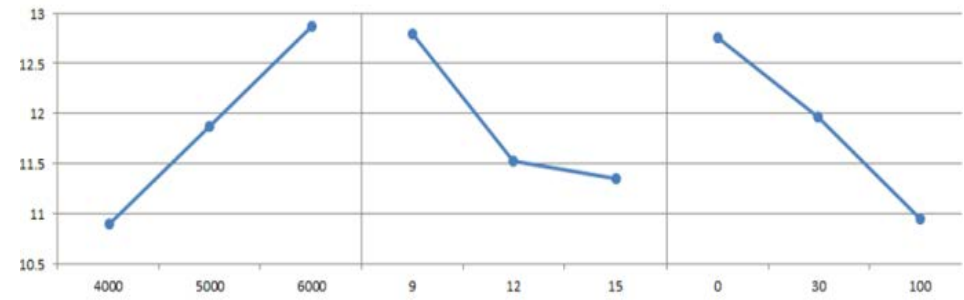

$\begin{array}{lll}\text { (a)Spindle speed } & \text { (b)Feed rate } & \text { (c) ultrasonic power level (\%) }\end{array}$

Fig. 11. $\mathrm{S} / \mathrm{N}$ ratio of surface roughness for final finishing in cycloid paths.

Therefore, the L16 Taguchi experiments are conducted by using the tool with rough abrasives of \# 400 meshes. The major contribution factors for enhancing material removal rate (MRR) are grinding depth $>$ spindle speed $>$ feed rate. The optimized combination by ANOVA is the set of spindle speed $5000 \mathrm{rpm}$, feed rate $5 \mathrm{~mm} / \mathrm{min}$, grinding depth of $12 \mu \mathrm{m}$, with flexible tool holder, and with ultrasonic assistance. Its highest MRR can reach up to $0.72 \mathrm{~mm} 3 / \mathrm{min}$. For the quality of surface roughness (SR), the main contribution factors are kinds of tool holder $>$ grinding depth $>$ spindle speed. The optimized parameters are under spindle speed $5 \mathrm{k} \mathrm{rpm}, 5 \mathrm{~mm} / \mathrm{min}$, depth $3 \mu \mathrm{m}$, with a flexible tool holder, and without ultrasonic assistance. Its minimum roughness reaches up to $\mathrm{Sa} 0.44 \mu \mathrm{m}$ in a good machinability.

The better performance of the carbide conducted through the cycloidal flexible grinding with rotary ultrasonic spindle was shown in Figure 13. The predicted surface roughness Sa is computed as $0.172 \mu \mathrm{m}$. While the confirmation experimental obtaining from the DOE by Taguchi method are Sa roughness of $0.185 \mu \mathrm{m}$, with residual error $7.6 \%$ comparing with that predicted surface roughness. And the flatness is $0.29 \mu \mathrm{m}$, respectively. As shown in Figure 13 (b), along the measuring of $15.44 \mathrm{~mm}$ length on the surface, there remained trivial revolution marks of tool path. The terrain caused by tool marks was risen from - 0.41 $0.20 \mu \mathrm{m}$. It was caused by the tool inclination and the vibration of the abrasives on the tool tip.
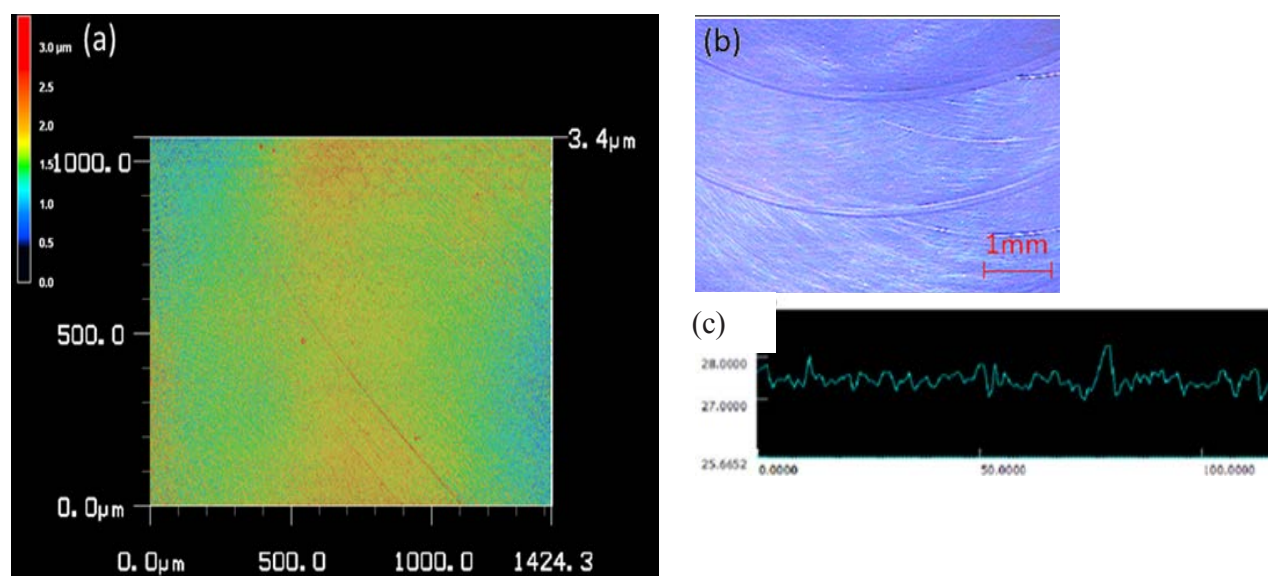

Fig. 12. (a) Surface of tungsten carbide after cycloidal path polishing with (b) macro view, and (c) its profile remained. 


\section{Conclusions}

Form above discussion, it is confirmed the novel flexible abrasives tool combined with a RUM spindle is feasible to achieve good surface integrity, and reduce the labor force with regular $\mathrm{CNC}$ machining. For the fundamental grinding survey by using abrasives of $13 \mu \mathrm{m}$ grits and $3 \mu \mathrm{m}$ of depth at that $7 \mathrm{k} \mathrm{rpm}$ combined with the RUM, surface roughness reaches about $\mathrm{Sa} 0.25 \mu \mathrm{m}$, which is $24 \%$ better than conventional no-RUM polishing. It is worthy noticed that $\mathrm{Z}$-axis resistant force increases with the increasing grinding depth, and decreases with the spindle speed. Generally, the polish force by using RUM is smaller than that by no-RUM, and their difference gets larger as the polish depth gets deeper. The surface roughness also decreases with the increasing spindle speed and the deceleration of the feed rate, respectively.

For further finish polishing, Taguchi design and ANOVA analysis reveal that for cycloid path, with feed rate of $9 \mathrm{~mm} / \mathrm{min}, 6000 \mathrm{rpm}$ and without RUM can reach the best flatness of $0.29 \mu \mathrm{m}$, and the lowest surface roughness of Sa $0.185 \mu \mathrm{m}$ with reasonable tool life. Based upon the above results, therefore, this paper confirms the feasibility of the newly designed flexible tool and contributes this hybrid polishing strategy of the tungsten carbide.

\section{Acknowledgement}

Financial support from both Tongtai machine \& tool Co., Ltd and National Kaohsiung University of Science and Technology, and the technology support from Dr. H.P. Chen and Mr. M.J. Chang are gratefully acknowledged.

\section{References}

1. P. Legge, Ultrasonic drilling of ceramics, Ind. Diam. Rev. 24, 20-24 (1964)

2. Mohsen Ghahramani Nik, Mohammad R. Movahhedy, Javad Akbari, Ultrasonic-assisted grinding of Ti6Al4V alloy, Procedia CIRP, 353-358 (2012)

3. Hu Gong, F.Z. Fang, X.T. Hu, 2010, Kinematic view of tool life in rotary ultrasonic side milling of hard and brittle materials, Int. J. of Mach. Tools and Manuf. 50(3), 303-307 (2010)

4. J.Y. Shen, J.Q. Wang, B. Jiang, X.P. Xu, Study on wear of diamond wheel in ultrasonic vibration-assisted grinding ceramic, Wear 332-333, 788-793 (2015)

5. B. Guo, Q. Zhao, Ultrasonic vibration assisted grinding of hard and brittle linear microstructured surfaces, Prec. Eng. 48, 98-106 (2016)

6. M. Fauzi Ismail, K. Yanagi, H. Isobe, Geometrical transcription of diamond electroplated tool in ultrasonic vibration assisted grinding of steel, Int. J. Mach. Tools \& Manuf. 62, 24-31 (2014)

7. Taghi Tawakoli, Bahman Azarhoushang, Influence of ultrasonic vibrations on dry grinding of soft steel, Int. J. Mach. Tools \& Manuf. 48, 1585-1591 (2008)

8. Y. Wang, B. Lin, X. Cao, S. Wang, An experimental investigation of system matching in ultrasonic vibration assisted grinding for titanium, J. Mater. Proc. Tech. 214, 1871-1878 (2014)

9. Y. Wang, B. Lin, S. Wang, X. Cao, Study on the system matching of ultrasonic vibration assisted grinding for hard and brittle materials processing, Int. J. Mach. Tools \& Manuf. 77, 66-73 (2014)

10. P. Hu, J.M. Zhang, Z.J. Pei, C. Treadwell, Modeling of material removal rate in rotary ultrasonic machining: designed experiments, J. Mater. Proc. Tech. 129, 339-244. (2002)

11. C.J. Wang, Albert W.J Hsue, The optimal combination of operational conditions and the tool wear characteristics of direct coupled rotary ultrasonic machininng, Proceedings of the Conference ICPMMT 2015, Kenting, Taiwan, May 21-24 (2015) 